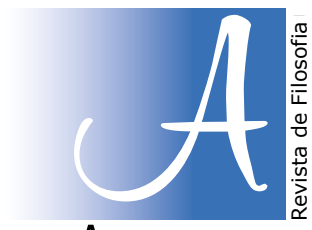

ARGUMENTOS

\title{
As alusões a primeira parte de Assim falou Zaratustra nas Cartas de Nietzsche: a criação como perspectiva artística e educativa
}

\author{
Allusions the first part of Thus spoke Zaratustra in Nietzsche's \\ letters: creation as and educational perspective
}

Enoque da Silva Peixoto

https://orcid.org/0000-0003-4687-2018 - E-mail: enockpeixoto@hotmail.com

\begin{abstract}
RESUMO
Durante os anos de 1881 e 1885, Nietzsche teve as primeiras intuições, escreveu e publicou a obra Assim falou Zaratustra. No presente texto, nos deteremos às circunstâncias que ladearam este acontecimento tendo como base as correspondências que o filósofo escreveu para várias pessoas no período. Serão abordados apenas os momentos iniciais nos quais se retrata o Zaratustra, quando o pensador alemssão destaca a relação sempre presente nas missivas, entre pensamento e natureza; estabelece proximidade entre o ato de escrever, atividade que ele entendia como tarefa, ao pensamento e a vida. Nietzsche avaliou também os seus problemas pessoais de saúde e ao mesmo tempo, o da debilidade coletiva, o que exigia uma "ajuda a si mesmo",para enfrentar tanto as enfermidades pessoais, como aquelas impostas pela vida gregária. A arte, nas suas diversas manifestações, mas, sobretudo a música figuraram como meios educativos e curativos, através dos quais ele pode buscar impulso para criar, para ser um soldado, capaz de dar vida a uma obra pujante, como o Zaratustra. Um livro sério e alegre, gestado dentro de uma ambiência particular e social na qual era necessário transformar "o sofrimento em ouro".
\end{abstract}

Palavras-chave: Educação. Arte. Sofrimento. Criação. 


\section{ABSTRACT}

During the years 1881 and 1885, Nietzsche had his first intuitions, wrote and published the work Thus spoke Zarathustra. In the present text, we will focus on the circumstances that bordered this event based on the correspondences that the philosopher wrote to several people in the period. Only the initial moments in which the Zarathustra is portrayed will be addressed, when the German thinker highlights the relationship that is always present in the missives, between thought and nature; it establishes proximity between the act of writing, an activity that he understood as a task, with thought and life. Nietzsche also assessed his personal health problems and, at the same time, that of collective weakness, which required "help to himself", to face both personal illnesses and those imposed by gregarious life. Art, in its diverse manifestations, but, above all, music figured as educational and curative means, through which he can seek impulse to create, to be a soldier, capable of giving life to a powerful work, such as the Zarathustra. A serious and cheerful book, created within a particular and social environment in which it was necessary to transform "suffering into gold".

Keywords: Education. Art. Suffering. Creation.

\section{O período da escrita do primeiro Zaratustra ${ }^{1}$}

Na carta 370 a Heinrich Köselitz, Nietsche faz alusão clara ao Zaratustra. Sustentamos que a menção a Assim falou Zaratustra ocorrera desde 1881; mas as referências diretas só aparecerão novamente em 1883, período em que o filósofo se debruça sobre a escrita do texto. As menções ao mesmo são constantes. Durante um tempo significativo, a abordagem do livro será o tema central das missivas trocadas com os seus interlocutores. Em carta a Heinrich Köselitz (carta 370), em 01 de fevereiro destaca: “É um livro pequeno - cerca de cem páginas impressas. Mas é o melhor dos meus livros, e para mim isso significa ter tirado um grande peso do meu coração. Nunca escrevi nada mais sério e alegre." Destaca ainda que o livro será intitulado: Assim falou Zaratustra, um livro para todos e para ninguém. Entendia que a partir daquele momento ele seria, certamente, incluído entre os loucos na Alemanha. Ele escreveu a máquina, no mês de janeiro daquele ano, a primeira das quatro partes do Zaratustra, em Ligúria, no noroeste da Itália (Cf. KSA, 15, 133). Ao editor Schumeitzner, na carta de 13 de fevereiro de 1883, diz que o livro era como uma poesia, como um "um quinto evangelho", para o qual ainda não existia definição. Trata-se da sua obra mais séria e mais alegre, além de ser acessível a qualquer pessoa.

Na esteira da reflexão sobre o nascimento de Assim falou Zaratustra, Nietzsche aborda a relação pensamento/natureza, significativa para a concepção do livro. Na missiva 373 a Franz Overbeck afirma: "eu, com minha maneira de pensar tão ligada aos fenômenos físicos, me considero vítima de um distúrbio climático-terrestre ao qual a Europa está exposta." Na carta de 19 de fevereiro de 1883 (carta 381), Nietzsche escreve a Köselitz que aquele inverno era o pior de sua vida e se considerava vítima de uma alteração da natureza. Destaca a seguir que as condições

\footnotetext{
10 presente texto integra a tese doutoral defendida pela Universidade Estadual do Rio de Janeiro- UERJ, cujo título é: As correspondências de Nietzsche e a educação em Assim falou Zaratustra: um processo de educação-estética. Salientamos que algumas argumentações neste texto fazem parte de um breve ensaio publicado na coletânea de textos Nietzsche e as Cartas, editado pela Via Verita, no ano de 2019: PEIXOTO, E.S. As cartas de Nietzsche no período da feitura do Zaratustra: A autossuperação como perspectiva educativa. In: Nietzsche e as Cartas. Org: Marina Gomes de Oliveira, Rosa Maria Dias. Rio de Janeiro: Via Verita, 2019.
} 
atmosféricas eram para ele um peso, mas naquele inverno rigoroso ocorreram dez dias serenos e agradáveis e neste período nasceu o seu Zaratustra. Atentemos aqui para a correspondência que o filósofo estabelece entre o ato criador, ou seja, entre a escrita de sua obra e o clima. Ele definhava de suas forças físicas e psicológicas, mas dez dias de claridade, de luz, foram suficientes para gestar parte do que considerava sua obra principal. A experiência vivida e sofrida no próprio corpo gerou a busca da superação. Neste contexto, transformara a sua dor em filosofia.

Tais reflexões que relacionam clima e pensamento, também aparecerão nas obras publicadas, como podemos atestar no último livro, de 1888, Ecce homo. Desde a primeira obra publicada até a última, tal perspectiva integra a filosofia nietzschiana. De um corpo frágil emergem criações vitais e vibrantes!

É neste contexto que defendemos a hipótese de que a filosofia nietzscheana na fase da maturidade, contém uma perspectiva educativa, pois a reflexão filosófica e a vida estão sempre unidas, concordamos com Parmeggiani para quem, "raramente houve uma integração tão compacta entre a escrita e a vida de um filósofo" (PARMEGGIANI, 2010, p. 30). Nietzsche pensa a vida na perspectiva da autossuperação. Havia um sofrimento constante do autor provocados pela sua frágil saúde, pelo tempo, pelo céu cinza, pela mãe e a irmã, pelo distanciamento dos amigos, pela solidão. Mesmo assim, ele se dispunha a criar, a levar adiante a sua tarefa. A Malwida von Meysenbug (carta 382) assevera: "Terei que provar mais uma vez meu antigo e rigoroso regime autoimposto: uma vez que a experiência me diz: 'Se você não sabe como se ajudar, não encontrarás ajuda." Andrade entende que este procedimento de ajudar a si mesmo vai além de uma questão egoísta, o filósofo está enfrentando a normatividade coletiva, as imposições dos sistemas de poder que controlam o discurso sobre o que é saúde ou doença:

[...] Nietzsche submeteu o saber médico a si, alterando-o de modo que tudo em sua condição e em sua história, inclusive sua doença e sua hereditariedade, aparecesse como sintoma ou como parte de uma vida ascendente. Ele colocou a si mesmo no centro desse saber, ocupando o espaço que antes pertencia à norma. Assim constituiu uma dimensão de sua experiência enquanto sujeito que, mesmo engajada em jogos de verdade, deslocava-se, ao menos parcialmente, das determinações dos dispositivos disciplinares e da maquinaria bioregulamentadora, uma dimensão cuja individualidade escapava ao esquadrinhamento destes complexos de saber-poder (ANDRADE, 2007, p. 124).

O filósofo elabora a noção de uma medicina a partir da percepção que tinha de si, como corpo específico pelo qual se podia medir o grau de intensidade ou fraqueza, mas também como a capacidade de perceber no seio de um povo o aspecto saudável ou degenerativo: "em todo filosofar, até o momento, a questão não foi absolutamente a 'verdade', mas algo diferente, como saúde, futuro, poder, crescimento, vida" (FRIEDRICH, 2001, § 2). Construir um saber sobre a saúde baseado na verdade médico-social vigente gerava diagnósticos abstratos, dissociados da vida real. As questões vitais: saúde-crescimento-futuro-poder-vida contestam o filosofar que impõe um saber distante do devir, das pulsões pujantes ou enfraquecidas presentes na sociedade.

Na carta 384, além de defender que precisava se ajudar, caso contrário estaria perdido, lamenta ter uma vida tão debilitada, justamente ele, que se considerava um "advogado da vida." Essas noções que aparecem no Zaratustra, em $O$ Adivinho e $O$ convalescente. ${ }^{2} O$ filósofo parece indagar: como alguém que ama a vida, que a afirma com todas as forças, que a defende contra todos os idealismos, pode conter no próprio corpo todas as razões para negá-la, maldizê-la? A resposta a este problema pode ser encontrada na tese de que todas as dimensões do existir são

\footnotetext{
${ }^{2}$ Trata-se de seções da obra Assim falou Zaratustra que está dividida em quatro partes.
} 
louváveis, conforme atesta Verônica Azeredo: "pois se a vida possui como traço fundamental o combate, o jogo de forças, as ameaças naturais de sofrimento e de dor, não podem ser interpretadas como isoladas da saúde, da alegria, e da felicidade" (AZEREDO, 2011, p. 252-253).

A inocência de tentar corrigir os defeitos da natureza, criando a ilusão de que há nela graus de perfeição, é quimérica para Nietzsche, pois as diversas coisas, as boas e ruins, estão misturadas no embate tensional e constante de todas as forças vitais. No entanto, o próprio filósofo reconhece que caía em enganos: "Meu erro no ano passado foi renunciar à solidão. Minha exclusiva convivência com imagens e fenômenos ideais me deixou tão irritável que nas relações com os seres humanos atuais padeço sofrimentos incríveis e um enorme sentimento de privação [...]." O retorno aos homens, imagem que remete à primeira parte do Zaratustra, também era fonte de dor. Ficou decepcionado com Lou, em quem ele depositara confiança. ${ }^{3}$ Estava frustrado com Wagner que se potencializava como lembrança dolorosa, em razão de sua morte. Na carta 384 Nietzsche afirma que Wagner o ofendeu mortalmente pelo seu retorno ao cristianismo e à igreja: "Toda a minha juventude com suas aspirações parecia contaminada, porque eu havia prestado homenagem a um espírito capaz deste passo." Neste contexto, o único caminho de "salvação" era buscar curar-se por si mesmo, não apenas na cura física, mas também existencial.

Na missiva 384 ele alude ao Zaratustra que caminhava para a edição. Trata-se da primeira parte do texto e na mesma carta analisa os seus objetivos se a sua proposta de viver recluso, de assumir a solidão como modo de vida: "Minha vida está gradualmente tomando forma e não sem espasmos [...]." Lembra o propósito de Cosima Wagner em viver reservadamente após a morte de Richard Wagner. Ele pretendia fazer algo semelhante, pois no final da carta menciona que buscava dar forma a própria vida. Menção ao seu permanente esforço em "dar estilo ao próprio caráter"; estabelecendo um modo de existir adequando o que se pensa ao que se vive. A solidão era o meio mais apropriado, naquele momento, para concretizar essa proposta.

Em seu contínuo envolvimento com questões artísticas, elabora um poema enviado ao músico Friedrich August Bungert escrito na capa do livro Aurora, provavelmente presenteado ao novo amigo. Este merece ser reproduzido, pois condensa não só o sentimento do filósofo em relação à arte, mas também em relação à vida (carta 388a):

\section{Quem algum dia terá que proclamar muito cale muito dentro de si: Quem algum dia terá que acender o raio Deve por muito tempo - ser nuvem.}

O proclamar muito e o acender um raio, devem ser antecedidos pelo calar e pela nuvem. Isso sugere que para falar é necessário antes, cultivar momentos de meditação e de aprofundamento, de estudos que possam fundamentar adequadamente a fala. Para além do conhecimento e da informação, tão caros a Nietzsche, estudioso constante de temas diversos; é necessário "ouvir a vida," o que ela revela a si mesma e sobre nós. As experiências, boas e nocivas são os meios mais adequados para gerar a palavra. Quem acende um raio, ou seja, transmite de algum modo o aspecto explosivo e tenso do real não como algo nocivo e destrutivo, no sentido

\footnotetext{
${ }^{3} \mathrm{Na}$ fase juvenil da vida de Nietzsche, ele foi amigo do músico Richard Wagner e acreditou que a sua arte traria uma renovação para a cultura alemã. Percepção que arrefeceu na fase madura e uma das razões que as cartas evidenciam para este rompimento foi o fato da obra de Wagner ter se tornado uma espécie de catequese cristã. Aconteceu rompimento também, com a russa Andrés Lou-Salomé, amiga e confidente do filósofo na juventude. A tensão entre ambos ocorreu, possivelmente, por causa de intrigas de Elizabeth, irmã do filósofo alemão.
} 
pessimista, mas criador e construtivo terá que ter entendido que a existência é também lutas e combates, é nuvem e não somente sol e céu claro.

A carta 390 a Heinrich Köselitz, assim como ocorreu em outras missivas do ano de 1883, continua destacando as características do músico antes citado, autor de várias óperas, Friedrich August Bungert. Antonio Marques comenta que ele era próximo da casa real romena e contribuiu para levar o filósofo "a reflexões sobre a estética musical," as quais Köselitz foi o principal receptor (MARQUES, 1996, p. 92). Nietzsche concorda em geral com essas reflexões e as suas perspectivas do artista trazem dados para pensarmos a questão estético e educativa:"Ele é uma pessoa independente. Até agora não encontrei nada mórbido nele. Tem fogo por dentro e valor para enfrentar os esforços mais comprometidos. Tem princípios rígidos, que coincidem incrivelmente com os nossos." Ter altivez, assim como Nietzsche reconhecia em si e nos amigos, era uma questão essencial. Parece adequado interpretar que sua postura de independência, de princípios rígidos, de coragem para enfrentar aquilo que já está cristalizado, reverberava em sua música. "Ele é poeta. Sua cabeça está plena dos mitos dos heróis gregos, e seus esboços são extraídos daquele mundo de sentimentos em que nasceu a poesia de Esquilo e Sófocles."

Para o filósofo, o novo estilo da composição o agradara porque, entre outros aspectos, a peça exigia que todas as notas fossem indispensáveis. $O$ autor era um poeta inspirado pela cultura grega clássica. Na carta seguinte (391), essa temática continua e Nietzsche se admira da capacidade e conhecimento poético do músico em questão: “Com quanta força e quanta engenhosidade ele é capaz de recitar um poema! Os músicos, logicamente, devem ser seus melhores intérpretes." Estabelece-se a relação entre música e poesia. Os músicos deveriam ser os meIhores intérpretes da poesia. Essa hipótese está certamente associada à necessidade de a música ter um efeito poético e a poesia um efeito musical. Mas a valorização dessa obra tinha restrições. O filósofo, na continuidade da carta, admite a sua lentidão e desconfiança para enamorar-se com algo, valorizara a noção de que a música é "delírio com a razão." Isto pode significar que a paixão está presente em sua obra, mas não uma paixão histérica, sem harmonia e ordem, mas uma paixão que delira com a razão, parece significar que entra em embate com ela, sem dela prescindir.

Arte, como as cartas demonstram, era permanente fonte inspiradora para Nietzsche. A missiva 392 a Heinrich Köselitz retoma esta íntima proximidade. Afirma que começara a compor os cantos de Dionísio, ${ }^{4}$ sob influência da ópera Carmem:

Comecei a compor sem interrupção, cantos de Dionísio, nos quais tomo a liberdade de dizer as coisas mais terríveis de uma maneira terrível e cômica: essa é minha última forma de loucura. Se pelo menos eu pudesse ensinar ao Sr. Gumbert parte dessa música, perdão! Bungert [...]. Eu acho que certa "distância" já foi criada entre nós; e enquanto ouvia novamente Carmen, estava ainda "mais distanciado".

A música de Bizet causara inspiração, não para sucumbir, mas para criar. Refere-se a uma forma de última loucura, assim como ele entende que foi pensada a composição do Zaratustra. As coisas mais terríveis, nos Cantos de Dionísio, eram ditas do modo mais cruel e cômico que ele interpreta em seu canto pelo que indica o seguimento do texto foi a interferência direta dos efeitos que a música Ihe causara. Contrastava com a música de Bungert que critica devido ao seu idealismo. A mesma repulsa idealista na contraposição que fazia entre Carmen e à música de Wagner, é o que assevera Mariano Gonzáles:

\footnotetext{
${ }^{4}$ A coleção de poemas “Ditirambos de Dionísio" veio a ser publicada somente em 1888.
} 
Acontece que a ópera de Bizet torna visível, da forma mais clara possível, o efeito deprimente das obras de Wagner. A objeção de Nietzsche seria fisiológica: como decadente que é, o músico alemão tem de pôr o belo e o sublime onde a vida ascendente poria simplesmente o irreal, o nada. [...] desejar a paz do cemitério, o sábado eterno, fora deste mundo tão sujo e tão baixo, tão doloroso: tudo isso se traduz nas óperas wagnerianas na grande oportunidade que elas nos brindam de esquecermo-nos de nós mesmos durante quatro ou cinco horas. Por isso Carmen contra Wagner pode ser considerado como o lema mesmo do pensamento nietzschiano, sua divisa: contra a decadência, o realismo, ou seja, a reconstrução do conceito [...] (GONZÁLEZ, 2017, p. 137).

Carmen e os Cantos de Dionísio cantam a vida, o seu poder criativo e destrutivo simultaneamente. A primeira foi inspiração didática para alavancar o fundo, mas, mais do que o fundo, Nietzsche repete duas vezes que se tratava de um fundo profundo. Não é o nosso lado mais original, oriundo da meditação racional, mas aquele advindo das entranhas, de uma potência desconhecida, assustadora. Neste processo, o ser humano precisa ter propósito, instigação para não sucumbir. Mas de onde vem esta força, este impulso? A carta 394 a Köselitz talvez elucide a questão:

Tenho refletido sobre o que você chama de motivo. Cheguei a pensar que é a música que não é criada, mas que é tomada: a música popular. Já foi demonstrado que as árias mais populares de Bellini (e também as de Paisiello) extraem seu tema das canções que são cantadas por Catania [...]. Parece-me que o "motivo" é, no âmbito da música, o que é usualmente chamado de "coro". O que você acha disso? Isso me traz a mente o meu Zaratustra.

Conclui que a música teve como motivo, como gênese, a canção popular. Não teria sido, então, fruto apenas da genialidade de Belline, Paisiello ou Homero; eles teriam constituído suas canções a partir de certa perspectiva de vida presente na conjuntura social. O "coro" seria o motivo que move a produção musical. Ele termina essas reflexões afirmando que tudo isto o fazia lembrar do Zaratustra. Esse é outro aspecto que entendemos que seja estético e educativo. Para Nietzsche essa obra teria emergido da experiência popular. Nesta conjuntura parece correto suster: assim como as árias populares serviram de base para grandes poetas e músicos, afirmar que estes pensamentos relembrarem Zaratustra pode significar que o livro não foi fruto somente da capacidade inventiva de seu autor, mas revela determinada força presente na textura social, manifesta como canto, como "coro." Compreende como fonte originária da arte uma abundância de vida, presente em determinado povo, que a arte é capaz de traduzir. Uma educação perpassada pela arte é ser capaz de ler essa potência da vida, criar uma linguagem, um meio de expressão para as manifestações mais singulares que emergem do povo. Os poetas citados, assim como Zaratustra, tendiam a ser um instrumento de expressão dessa vitalidade.

\section{A criação: alquimia que transforma o sofrimento em ouro}

A Heinrich Köselitz, na carta 401, Nietzsche evidencia mais uma vez a associação entre superação e criação: “Caro amigo, você não pode imaginar que carga excessiva de sofrimentos jogou a vida sobre mim, em todas as épocas, desde a minha infância. Mas eu sou um soldado: e este soldado ao final de tudo se tornou o pai de Zaratustra!" O filósofo se admirara da carta do amigo, na qual rebatera a posição de Nietzsche. Esse último lhe escrevera anteriormente e se descrevia como um fracassado; relembra sua penúria de longa data e que perpassara praticamente toda a sua existência, mas, salienta, viveu como um soldado. Viver como soldado sugere que não se tornou mercenário das ideias, curvando-se a um pensamento pessimista e negador 
da vida, mesmo com razões para fazê-lo. O seu próprio corpo negava constantemente o encanto da vida, no entanto, esse soldado deu vida ao Zaratustra. Lamenta ainda de o livro ter entrado no mundo como "um livro divertido". Duas afirmações precisam ser frisadas neste contexto, o pensador destaca inicialmente que percorreu uma longa existência marcada por mazelas físicas constantes, mas não sucumbiu, apesar de evidentes momentos de apatia. A feitura do Zaratustra demonstra o ímpeto para despontar uma obra vital de um corpo agudamente debilitado! Nietzsche não nega o lado obscuro da existência, reflexo que ele sentia na própria fisiologia, mas assim como os gregos-seus mestres- que transformaram as agruras da existência em arte, ele também se empenhou para adotar essa corajosa atitude. A sua indignação pela obra em questão estar sendo considerado divertido é outra questão a ser apontada, visto que se trata de um livro "sério e alegre," mas não cômico, estava, sobretudo, marcado pelo sofrer que se autossupera. É intenso como um parto. Trata-se de uma alegria que convive com a dor. Isso ocorre, na concepção nietzschiana, em todo ato de criação. O que estamos denominando como estético-educativo é exatamente este processo que o filósofo admite ter ocorrido durante toda a vida, o esforço em dar forma vital, criativa, bela a algo doloroso, feio, repulsivo. Isso é dar senso estético à própria vida!

O propósito de se mudar para Barcelona (carta 402), onde o clima era mais favorável à sua saúde foi um dos projetos de Nietzsche. Afirma que se sentia, assim como Köselitz, estranho à Europa vigente e para que desta sensação emergisse positivo seria necessária uma separação física também. Havia, então, a separação mental, o desacordo com o modelo de vida que prevalecia naquele momento, mas para emergir algo enérgico desta sensação, também era imperiosa. Não bastava ter consciência de que discordava do modo de viver, mas era necessário estabelecer distanciamento real, corporal, para que os efeitos daquela sensação fossem efetivos. Em 17 de abril (carta 403), novamente a Overbeck, exalta outra vez o clima e a sua mudança de humor por causa dele. Chega a afirmar que duvidava de suas decisões e reflexões sob efeito do inverno, mas em um "clima maravilhoso", a sua reflexão teria algum valor. Admite que a vida é dolorosa, mas estabelece uma meta pela qual valia a pena viver. Novamente se refere aos dez dias nos quais nasceu o seu livro principal:

Realmente, meu querido amigo, às vezes me parece que até agora eu vivi, trabalhei e sofri para conseguir fazer esse pequeno livro de sete folhas! Além disso, é como se minha vida recebesse justificativa depois disso. E, a partir desse momento, vejo com outros olhos, inclusive este inverno, o mais doloroso de todos: quem sabe se não era necessário um tormento tão grande para me determinar a sangria que é precisamente esse livro? Você entende que há muito sangue neste livro.

Nietzsche escreve a Malwida von Meysenburg (carta 404) e comenta um cartão postal que recebera de alguém que não especifica, apenas afirma que era um homem aparentemente razoável, um cético. Esse desconhecido definira o Zaratustra como história maravilhosa, que desafiara todas as religiões. Era um "novo livro sagrado," tão sério como qualquer outro livro sagrado e introduzira o riso na religião. $\mathrm{O}$ tema do riso, presente nas correspondências, aparece constantemente na obra escrita, como no aforismo 294 de Além do bem e do mal, quando destaca a função e o valor dele na filosofia:

O vício olímpico - A despeito daquele filósofo que como verdadeiro inglês caluniou o riso em todos os pensadores -"o riso é uma verdadeira enfermidade da natureza humana, que todo ser pensante deverá saber vencer" (Hobbes) - eu me permitirei instituir uma classificação dos filósofos segundo a classe a que pertence seu riso - até chegar àqueles que são capazes do riso áureo. E supondo que também os Deuses se ocupem com a filosofia, suposição à qual sou levado por várias razões - não duvido que saibam rir dum modo novo e sobre- 
humano - acerca das coisas mais sérias, inclusive! Os deuses sentem-se inclinados pelo escárnio, mesmo nas cerimônias sagradas parece que não podem conter o riso.

O autor do Zaratustra em muitos momentos admite o valor da seriedade, no entanto, ser sério não significa rudez, o pensamento é associado com a alegria de viver. Nisso consiste admitir a ausência de toda e qualquer fundamentação da realidade, a sua virulência pode derrubar as nossas certezas a qualquer momento, assim como ele acena em Assim falou Zaratustra: É necessário fazer uma coroa de rosas que ele afirma ter posto em si, ao declarar santa a sua risada (Cf. NIETZSCHE, 2011). O riso está envolto no esforço em compreender a noção de que a vida pode ser leve, dançarina, assim como Zaratustra. Trata-se de alguém que está livre das interpretações metafísicas, sejam aquelas que criam uma realidade transcendente para justificar o imanente; sejam aquelas, como a de Hobbes, fundadas na concepção de natureza humana. ${ }^{5}$ Para Nietzsche, portanto, nas concepções fixas e essencialistas, o riso fica dificultado. Conforme Rosa Dias: "O riso se apresenta como um recurso simbólico presente na concepção antimetafísica do mundo e se vincula ao projeto de superação da metafísica e de realização de uma interpretação da existência puramente intramundana" (DIAS, 2019, p. 81). O Zaratustra tem a vantagem de retirar a tensão e o medo do presente, atuante na maioria das doutrinas religiosas, celebrando uma "religião imanente." É alegre, valoriza a dança, a arte, zomba da própria vida, pois sabe que nela não há nada que devemos nos apegar de forma definida. O riso é saudável, pois independente de nossos propósitos, crenças, lutas, vitórias e derrotas. Ela, a vida, continuará triunfando, acima e alheia aos nossos desejos pessoais; servimo-la enquanto participantes de sua força construtiva e destrutiva.

Comenta com Köselitz, em 23 de abril, que naquele dia aprendera o significado da expressão Zaratustra: "Estrela de Ouro". Coincidência que o deixou feliz, embora até então, ele não soubesse que a concepção do livro teria se baseado nessa etimologia. "Transformar a dor em ouro," este foi o esforço de Nietzsche durante toda a sua vida e especialmente neste momento difícil de sua existência. Na carta 365 de 1882, ao escrever para Overbeck sobre os sofrimentos que o assolavam, assevera: "Se não consigo inventar o artifício dos alquimistas para transformar essa lama em ouro, estou perdido. - Aqui tenho a mais bela oportunidade de demonstrar que, para mim, 'toda experiência é útil, cada dia santo e todo ser humano divino." O autor do Zaratustra é um tipo diferente de sofredor que vislumbra a existência de outra forma diversificada de sofredores ${ }^{6}$. Foi o momento mais conturbado da vida de Nietzsche, quando ele produziu a sua obra mais excelente.

A redenção não metafísica nietzschiana, a redenção imanente em uma vida que é necessariamente marcada pela dor, não ocorre ao agirmos de forma furtiva diante do existir, mas enfrentando os seus dissabores de modo criador. Se redimir é criar, é neste sentido que a arte salva a vida. Em 28 de maio de 1883 (carta 421), a Marie Baumgartner, o filósofo considera o

\footnotetext{
${ }^{5}$ O filósofo inglês Thomas Hobbes (1588-1679), considera que o homem em estado de natureza é extremamente violento, por isso a afirmação: "o homem é lobo do próprio homem". A função da criação artificial do Estado seria exatamente para que a vida coletiva seja possível e a dimensão, naturalmente violenta do homem, não domine; o que geraria a um embate constante: Afirma o filósofo: “Com isto se torna manifesto que, durante o tempo em que os homens vivem sem um poder comum capaz de os manter a todos em respeito, eles se encontram naquela condição a que se chama guerra; e uma guerra que é de todos os homens contra todos os homens. Pois a guerra não consiste apenas na batalha, ou no ato de lutar, mas naquele lapso de tempo durante o qual a vontade de travar batalha é suficientemente conhecida" (HOBBES, 1929, Capítulo XIII).

${ }^{6}$ Conforme o $\$ 370$ de $A$ Gaia ciência:"“...] existem dois tipos de sofredores, os que sofrem de abundância de vida, que querem uma arte dionisíaca e também uma visão e compreensão trágica da vida- e depois os que sofrem de empobrecimento de vida, que buscam silêncio, quietude, mar liso, redenção de si mesmos mediante a arte e o conhecimento, ou a embriaguez, o entorpecimento, a convulsão, a loucura". São os que sofrem por intensidade, para ter mais força, potência, e não os que confundem sofrer com aniquilamento, os sofredores que Nietzsche valoriza.
} 
Zaratustra como esposa e como filho: "Enquanto isso, minha querida esposa, meu "Zaratustra" estará sobre seu comando [...]" e também: "Pergunte ao meu filho Zaratustra, e se as desculpas de qualquer culpa fizerem isso, ele terá que me desculpar." Eis mais uma passagem na qual se destaca a feitura do Zaratustra como um ato de criação, mas que não se limita a uma relação distante do autor com o seu livro, mas uma criação que emerge das forças pulsionais mais intensas. Tratar o livro como esposa e filho remete ao ato gerador que está relacionado a estas duas experiências humanas. Nelas, o relacionamento afetivo é intenso, e mais do que uma mera proximidade social entre filiação e matrimônio, remete a criação artística.

Carl von Gersdorff é o destinatário da carta 427 do final de junho de 1883, em que o filósofo alemão em estudo lamenta e compartilha o momento de dor que o amigo passara pelo falecimento de sua mãe. Em seguida destaca novamente os sofrimentos dos últimos anos e a construção do Zaratustra:

Quanto a mim, tenho atrás um ascetismo longo e severo do espírito, ao qual me submeti por vontade própria, e que nem todos teriam sido capazes de suportar. Sob este aspecto, os últimos seis anos foram aqueles em que mais tive que me sobrepor, e digo isso sem ter em conta o que atravessei para superar a má saúde, a solidão, a incompreensão e a difamação. Seja como for, eu também consegui superar esta etapa da minha vida - e o que ainda tenho que viver (penso que pouco!); Servirá para expressar, completa e plenamente, as coisas pelas quais eu consegui suportar a vida. O tempo do silêncio terminou: desejo que meu Zaratustra, que deve ter sido enviado a você nestas semanas, descortine até que altura tem voado a minha vontade. Não se deixe enganar pela marca lendária deste pequeno livro: por trás de cada uma dessas palavras simples e incomuns há a minha mais profunda seriedade e toda a minha filosofia.

O ascetismo para o autor do Zaratustra não foi imposto de fora, mas surgiu como uma opção livre. Várias dificuldades foram suportadas e o filósofo destaca que o que ainda tinha para viver, serviria para expressar como conseguiu a superação de todos os obstáculos. Notemos que ele apresenta o seu esforço intelectual para traduzir e criar uma linguagem demonstrativa de como o sofrimento pode ser enfrentado, como a vida pode ser suportada. Merece ainda destaque, nesta carta a referência à seriedade do Zaratustra. Não se trata de um livro para entretenimento, mas que transmite uma visão artística: talvez por isso, podia (e ainda pode) causar o equívoco de ser interpretada estritamente como literatura, sem embasamento filosófico.

Nietzsche afirma que se trata de sua mais séria e profunda filosofia. Logo, o que ele denomina como sua filosofia visa a transformar em algo vital o esforço para suportar a vida. Interpretamos este movimento como estético-educativo, pois ele remonta a como o indivíduo Nietzsche se relacionou com situações particularmente dolorosas, dando a elas uma resposta afirmativa, tornando-as um modo de dizer sim à existência. É um processo de feitura, de moldar, pintar, ensaiar um passo de dança, encaixar adequadamente uma nota musical tendo como quadro, palco ou instrumento, a vida.

As correspondências que destacamos neste trabalho concentraram as alusões mais constantes a Assim falou Zaratustra. No campo da arte, se intensificam as críticas a Wagner, dentre elas, a questão do uso das palavras na música. O filósofo destaca a educação de si mesmo e o projeto de viver a solidão como modo de vida.O contato com a ópera de Carmen foi outro momento importante, pois serviu inclusive como contraponto ao anterior valor atribuído a obra de Wagner.

Demarcamos a alusão ao Zaratustra e a criação como gestação, onde o ato criador é apresentado como redenção. A partir das cartas, Nietzsche denuncia um modo decadente de assumir a vida, valorizando a criação, a emergência do novo, o predomínio de uma vida que é 
educativa por privilegiar um modo artístico de existir. Como isto ocorreria na prática? Assumindo modos originais de estar no mundo, deixando de se pautar pelo comportamento gregário, reinventando a si mesmo e, como o próprio Nietzsche efetivou - criando! Para ele, os seus livros foram o caminho para dar vazão a sua potência geradora, outros seres humanos, podem ter outros caminhos!

\section{Referências}

ANDRADE, D. P. Nietzsche: a experiência de si como transgressão (loucura e normalidade). São Paulo: Annablume, 2007.

AZEREDO, V. P. O. Nietzsche: a grande saúde e o sentido trágico da vida. Cadernos Nietzsche, São Paulo, n. 28, 2011, p. 249-261.

DIAS, R. M. Passagem nietzschiana. Rio de Janeiro: Mauad X, 2019.

DIAS, Rosa Maria; OLIVEIRA, Marina Gomes de [et al]. Nietzsche e as cartas. Rio de Janeiro: Via Verita, 2019.

GONZÁLEZ, Mariano Rodríguez. "Mantenha-se mediterrâneo!": Razões do entusiasmo de Nietzsche por Carmen. Cadernos Nietzsche, São Paulo, v. 38, n. 1, jan./abr. 2017, p. 127-147.

JANZ, Paul Curt. Friedrich Nietzsche. 4 vols. Tradução de Jacobo Muñoz. Madrid: Alianza, 1987.

MARQUES, Antonio. "No fundo sou todos os homens da história": Nietzsche: Os vinte anos fundamentais a partir de suas cartas. Círculo de Leitores, 1996.

NIETZSCHE, Friedrich. A gaia ciência. Tradução de Paulo César de Souza. São Paulo: Companhia das Letras, 2001.

NIETZSCHE, Friedrich. Além do bem e do mal. Tradução de Paulo César de Souza. São Paulo: Companhia das Letras, 1992.

NIETZSCHE, Friedrich. Assim falou Zaratustra, um livro para todos e para ninguém. Tradução de Mario da Silva. 18 edição, Rio de Janeiro: Civilização Brasileira, 2010.

NIETZSCHE, Friedrich. Assim falou Zaratustra, um livro para todos e para ninguém. Tradução, notas e posfácio de Paulo César de Souza, São Paulo: Companhia das Letras, 2011.

NIETZSCHE, Friedrich. Correspondencia IV Enero 1880 - Diciembre 1884. Traducción, introducción, notas y apéndices de Marco Parmeggiani. Editorial Trotta, Madrid, 2010.

NIETZSCHE, Friedrich. Correspondencia V Enero 1885 - Octubre 1887. Traducción, introducción, notasy apéndices de Juan Luis Vermal. Editorial Trotta, Madrid, 2011.

NIETZSCHE, Friedrich. Digitale Kritische Gesamtausgabe von Nietzsches Werken und Briefen. Edição organizada por Paolo D'lorio, baseada na edição crítica de G. Colli e M. Montinari e publicada pela Nietzsche Source. Edição eletrônica. Acesso em 01.abr.2020.

NIETZSCHE, Friedrich. Ecce homo: como alguém se torna o que é. Tradução de Paulo César de Souza. São Paulo: Companhia das Letras, 2008.

NIETZSCHE, Friedrich. Sämtliche Werke: Kritische Studienausgabe In: 15 Bänden. Edição organizada por G. Colli e M. Montinari. Berlim: Walter de Gruyter, 1999.

SALOMÉ, Lou Andres. Nietzsche e Lou. In: Correspondências e outros documentos - Introdução. Rio de Janeiro: Via Verita, 2019. 


\section{Sobre o autor}

\section{Enock da Silva Peixoto}

Doutor em Filosofia pela Universidade Estadual do Rio de Janeiro-UERJ; doutorando em Filosofia pela Universidade Federal do Rio de Janeiro-UFRJ; mestre em Educação pela Universidade Federal do Estado do Rio de Janeiro-UNIRIO; Docente na Secretaria de Educação do Estado da Bahia.

Recebido em: 05/11/2020.

Aprovado em: 23/02/2021.
Received: 05/11/2020.

Approved: 23/02/2021. 